\title{
Seismic Behavior of Fatigue-Retrofitted Steel Frame Piers
}

\author{
Kinoshita, K.1)
}

\begin{abstract}
Fatigue retrofit works have been conducted on severely fatigue damaged beam-tocolumn connections of existing steel frame bridge piers in Japan. It is clear that retrofit works provides additional stiffness but the significance on the seismic behavior of steel frame piers is not clear. Since fatigue retrofit works have become prevalent, the effect of fatigue retrofit works on the seismic behavior of steel frame piers need to be understood. The objective of this study is therefore to investigate these effects of the retrofit work, especially installation of bolted splices, which is the most common technique. Elasto-plastic finite element earthquake response analyses were carried out. It is shown that the existence of bolted splices may increase seismic demand on the piers when plastic hinge zone is located on the beam. In addition, longer bolted splices using low yield strength steel are proposed to overcome this problem and are shown to give beneficial effects.
\end{abstract}

Keywords: Beam-to-column connections, fatigue damage, fatigue retrofit works, seismic behavior.

\section{Introduction}

Steel frame piers are commonly used for highway viaducts or bridges in urban areas in Japan. It is observed that fatigue cracks occurred at beam-tocolumn connections of these frame piers [1], as shown like Figure 1. Causes of these fatigue cracks were experimentally investigated in previous studies [2-6]. As a result, in order to ensure good performance and safety of the structures, fatigue retrofit work techniques, such as drilling holes (Figure 2) and installing bolted splices, have been conducted on severely damaged beam-to-column connections [7-8].

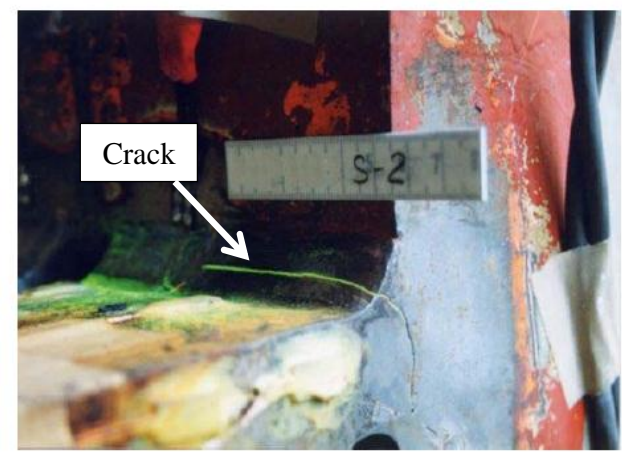

Figure 1. Fatigue Crack Occurred at Beam-to-Column Connection [1]

1 Department of Civil Engineering, Gifu University, 1-1 Yanagido, Gifucity, Gifu 501-1193, JAPAN.

E-mail: kinosita@gifu-u.ac.jp

Note: Discussion is expected before November, $1^{\text {st }} 2013$, and will be published in the "Civil Engineering Dimension" volume 16, number 1, March 2014

Received 21 March 2013; revised 13 April 2013; accepted 11 June 2013

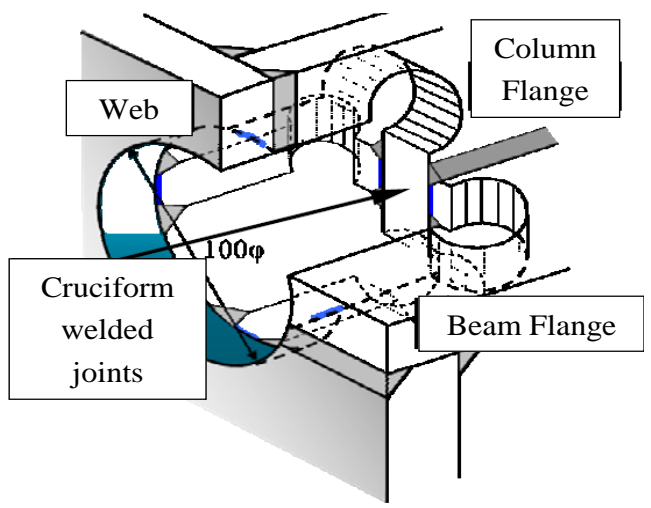

Figure 2. Drilling Hole of Fatigue Retrofit Work [8]

Despite the common practice of the fatigue retrofit works, their effects on the seismic behavior of the piers are poorly understood and there is no hard evidence that fatigue retrofit works are beneficial for seismic forces. Design procedures for fatigue retrofit works do not require the earthquake load to be considered. This decision is based on two major assumptions. First, it is likely that steel frame piers are able to perform well during large earthquakes, and second, seismic response of steel frame piers is concentrated in the columns plastic hinge zone and therefore effects of fatigue retrofit works are negligible. However, one of the important lessons learned from severe bridge damage in past earthquakes is that the beams of bridge pier systems are the weak part, as shown like Figure 3. The plastic hinge zone of the beam, which is located close to the beam-to-column connections, may be affected by the placement of the bolted splices. Therefore, those effects on the seismic behavior need to be understood.

This paper presents results from finite element (FE) earthquake response analyses on two actual existing steel frame piers to determine effects of adding bolted splices as a fatigue retrofit work technique, on their seismic behavior. 


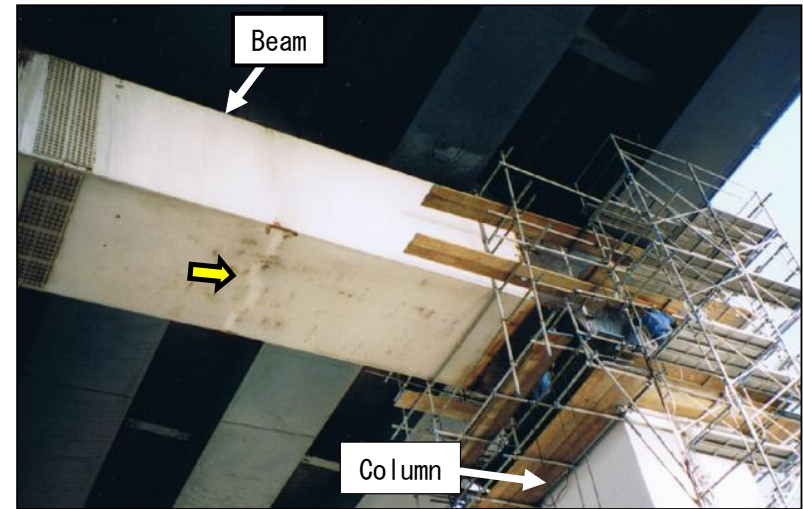

Figure 3. Damaged Steel Frame Pier, Kobe Earthquake, 1995

This paper also presents effects of a proposed method of using longer bolted splices using low yield strength steel [9], which enhances the seismic performance of these piers.

\section{Literature Review}

Morikawa et al. [1] reported fatigue cracks that occurred at beam-to-column connections of existing steel frame piers in the Tokyo Metropolitan Expressway System in 1997 and proposed the fatigue retrofit work technique, which is the addition of bolted splices, as shown in Figure 4. Following this report, Miki et al. [2-6] performed a series of study to determine the causes of these fatigue cracks. The studies included large-scale experimental works and numerical analyses. It was found that the causes of these fatigue cracks are incomplete penetration of weld joints and high stress concentration at the corner of the connections. Furthermore, another study on the effects of addition of bolted splices on strength and ductility of steel frame piers was done by Miki et al. [7]. Analyses were carried out on an actual existing steel frame pier with and without bolted splices under push-over loading. It was concluded that the strength and ductility were not affected by the bolted splices. In contrary, Shimozato et al. [8] investigated effects of bolted splices on strength and ductility of another actual steel frame pier and concluded that the bolted splices lead to larger deformation in the plastic hinge zone on beam, and this is the results of increase of seismic response and decrease of ductility.

Sasaki et al. [10], Miki and Sasaki [11] and author's previous studies $[12,13]$ conducted analytical investigations on seismic behavior of existing frame piers and showed that damage was found not only in columns but also in beams. Therefore, it is necessary to study the effect of addition of bolted splices on the damage of the beams during earthquakes. On the other hand, after the 1995 Kobe Earthquake, several seismic retrofit works were proposed and performed for existing steel frame piers [14].

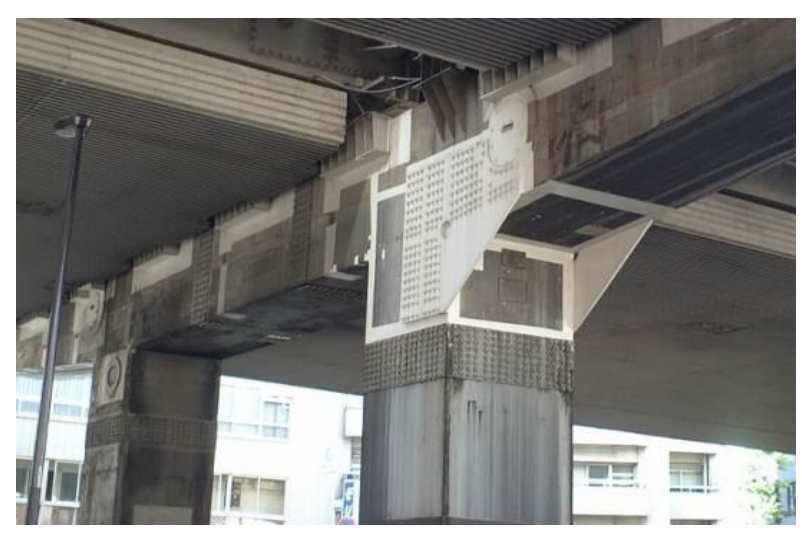

Figure 4. Steel Frame Pier with Fatigue Retrofit Work

However, those seismic retrofit works do not incorporate the effects of fatigue retrofit works and do not discuss its effects on the seismic behavior.

Konishi et al. [15] analytically investigated effects of bolted splices on stress at beam-to-column connection, and they provided a relationship between beam height $H$ and ratio of length $W$ to beam height $H$, as shown in Figure 5. Based on the curve-fitting of the data shown in Figure 6, the relationship is given as follows:

$\mathrm{W} / \mathrm{H}=6.6 \mathrm{H}^{2}-36.8 \mathrm{H}+77.0$

This relationship shows size of bolted splices, which can decrease the stress at the corner of the connections by $50 \%$. Based on this relationship, size of bolted splices can be determined.

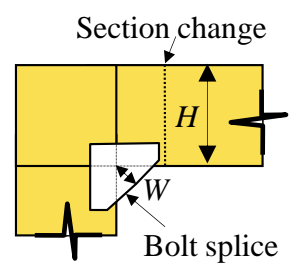

Figure 5. Dimension of Bolted Splice

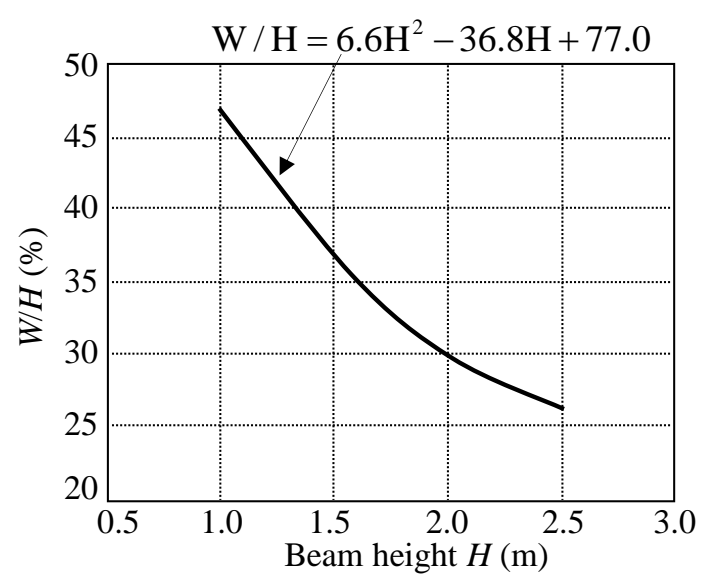

Figure 6. Relationship between $H$ and $W / H$ 


\author{
FE Modeling of Existing Steel Bridge Frame \\ Piers
}

\section{Frame Models}

Figure 7 shows the frame models, which are boxsection steel frame piers, as representative of existing steel bridge frame piers used in urban areas. Pier A has square columns with a flange width of 2.0 $\mathrm{m}$ and a web height of $1.5 \mathrm{~m}$ and a square beam with a flange width of $2.0 \mathrm{~m}$ and a web height of $1.8 \mathrm{~m}$. Pier B has square columns with a flange width of 2.0 $\mathrm{m}$ and a web height of $1.5 \mathrm{~m}$ and a square beam with a flange width of $2.0 \mathrm{~m}$ and a web height of $1.8 \mathrm{~m}$

\section{FE Models}

Figure 8 shows FE models, which were made in finite element analysis software ABAQUS [16]. The frames were modeled with shell elements. The minimum element size used at the corner of beamcolumn connections was approximately the same as beam flange thickness. The boundary conditions were:

a) fixed column base to represent the base that was anchored by high tension bolts.

b) symmetry at the center of the frames.

In addition, weight of the superstructure was modeled using mass elements, which were distributed to the bearings. The effect of live load is ignored in current seismic analysis as discussed by Wibowo et al. [17]. Last, as shown in Figure 8(c), bolted splices were connected to beam-to-column connections using rigid link elements.

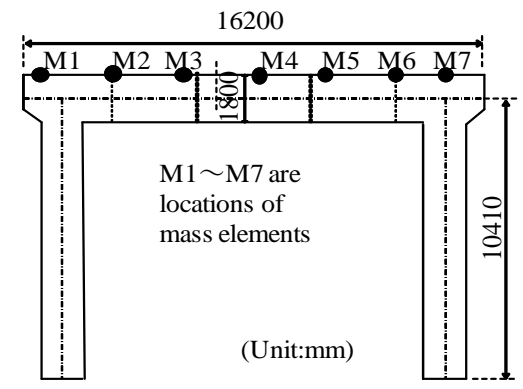

(a) Pier A

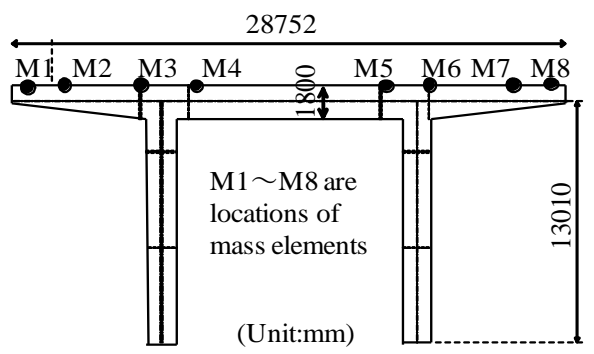

(b) Pier B

Figure 7. Frame Models

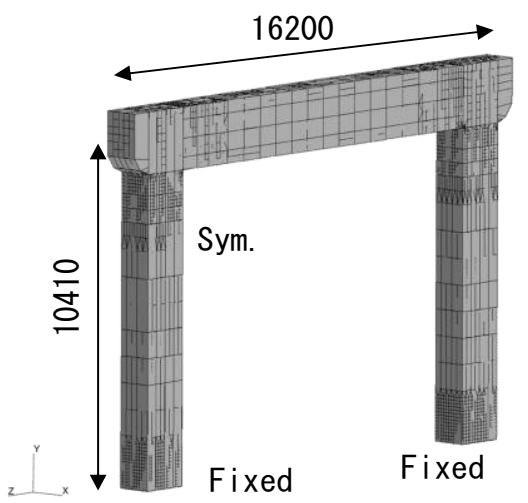

(a) Pier A

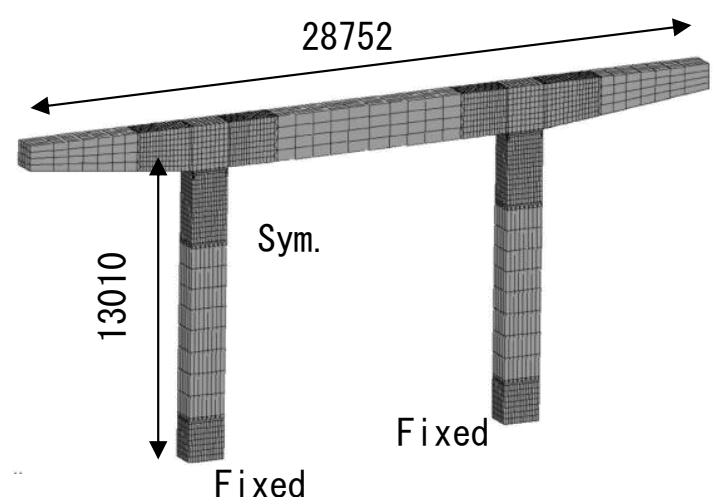

(b) Pier B

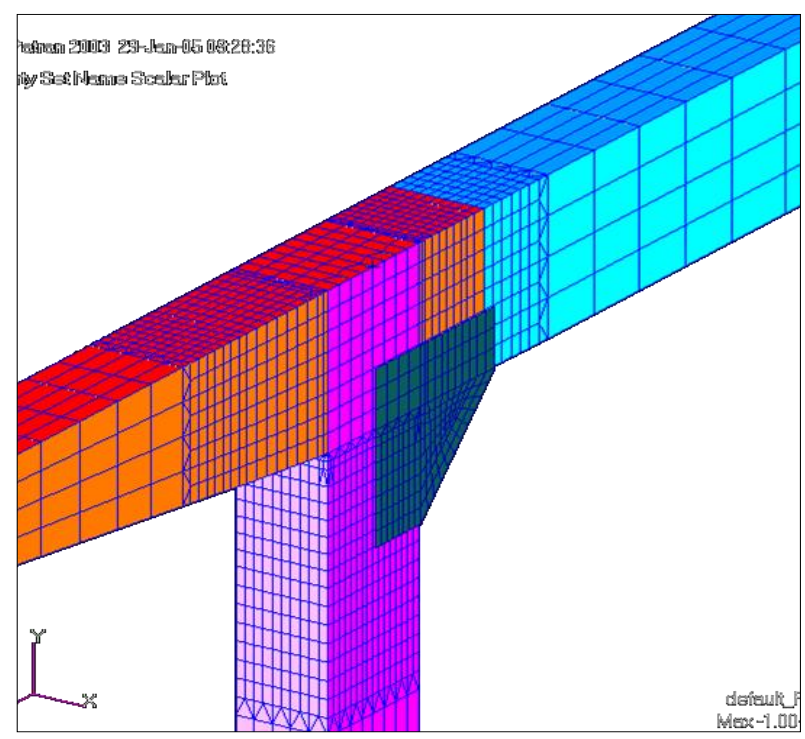

(c) Model of Bolted Splice

Figure 8. FE Models

Sasaki et al. [10] and Miki and Sasaki [11] previously investigated the seismic behavior of both Pier A and Pier B. Based on those studies, plastic hinge zone was observed at the columns of Pier A as shown in Figure 9(a) and at not only the columns but also the beam of Pier B as shown in Figure 9(b). Therefore, different seismic behaviors are observed and investigated in this study. 


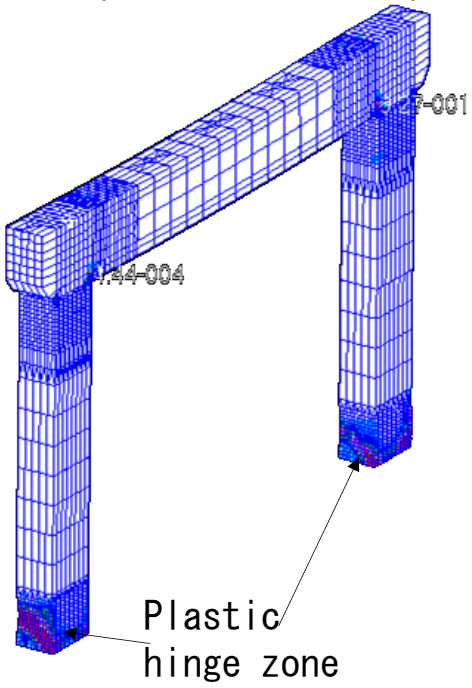

(a) Pier A

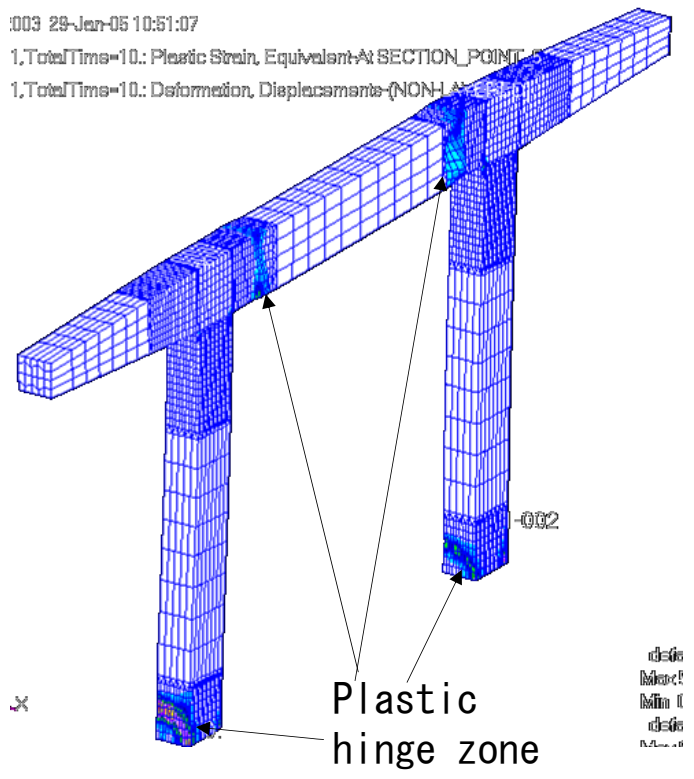

(b) Pier B

Figure 9. Deformation and Plastic Strain of Models after an Earthquake [10, 11]

\section{Analysis Cases}

Analysis cases are listed in Table 1. Two sizes of bolted splices: regular size and longer size, and two steel materials: regular steel and low yield strength steel were investigated. This parametric study tries to investigate effects of longer bolted splices, which can attract more seismic force to bolted splices, and the low yield strength steel, which can provide more damping, on the seismic response. Input motion for analyses was the JR-Takatori record from the 1995 Kobe Earthquake [18], as shown in Figure 10. The East-West (EW) and Up-Down (UD) components of the ground acceleration in the first 10 seconds of the record were applied together at the same time.
Table 1. Analysis Cases

\begin{tabular}{|c|c|c|c|c|}
\hline & Pier & name & Input & Parameter \\
\hline Case1 & & $\mathrm{A}-\mathrm{N}$ & \multirow{8}{*}{$\begin{array}{l}\text { JR- } \\
\text { Takatori }\end{array}$} & Without bolted splices \\
\hline Case2 & & A-SP & & With bolted splices \\
\hline Case3 & A & A-SPD & & $\begin{array}{l}\text { With bolted splices using low } \\
\text { yield strength steel }\end{array}$ \\
\hline Case4 & & A-SPD-E & & $\begin{array}{c}\text { With longer bolted splices using } \\
\text { low yield strength }\end{array}$ \\
\hline Case & & B-N & & Withou \\
\hline Case & & B-SP & & With bolted splices \\
\hline Case7 & B & B-SPD & & $\begin{array}{l}\text { With bolted splices using low } \\
\text { yield strength steel }\end{array}$ \\
\hline Case8 & & B-SPD-E & & $\begin{array}{l}\text { With longer bolted splices using } \\
\text { low yield strength }\end{array}$ \\
\hline
\end{tabular}

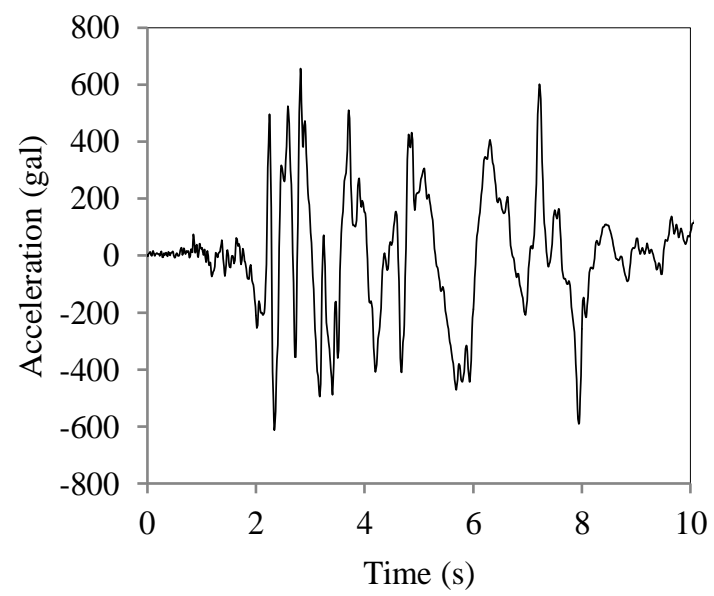

(a) EW Component

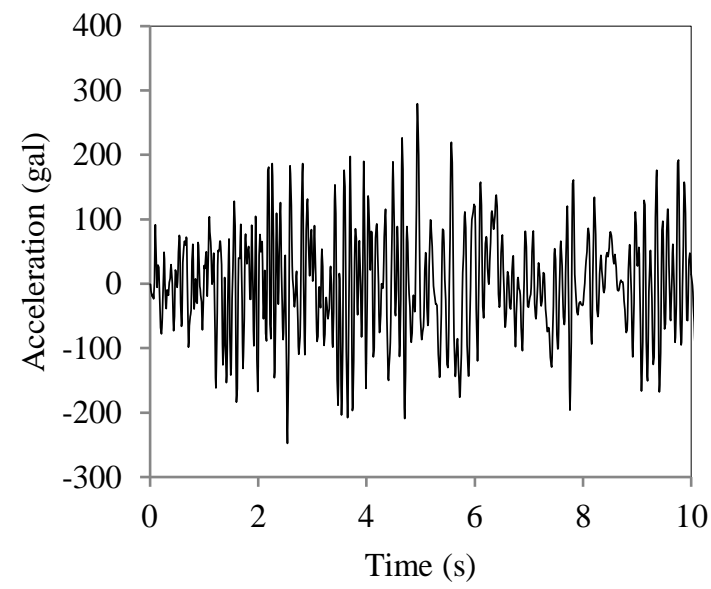

(b) UD Component

Figure 10. Input Ground Acceleration Histories

\section{Material Properties and Analysis Method}

Stress-strain curves of the steel materials, which are SS400 [19] and SM490Y [20] used in the analyses, are shown in Figure 11. These relationships were determined based on the document by the Committee of Steel Structures of JSCE, JSSC [21], which are given as follows: 


$$
\begin{aligned}
& \frac{\sigma}{\sigma_{y}}=\frac{1}{\xi} \frac{E_{s t}}{E}\left\{1-e^{-\xi\left(\varepsilon / \varepsilon_{y}-\varepsilon_{s t} / \varepsilon_{y}\right)}\right\}+1 \quad\left(\varepsilon \geq \varepsilon_{s t}\right) \\
& E^{\prime}=\frac{d \sigma}{d \varepsilon}=E_{s t} \cdot e^{-\xi\left(\varepsilon / \varepsilon_{y}-\varepsilon_{s t} / \varepsilon_{y}\right)}
\end{aligned}
$$

where $E^{\prime}$ is the tangent modulus and $\xi, E / E_{s t}$, and $\varepsilon_{s t} / \varepsilon_{y}$ are the constants for each grade of steel. Yield stress $\sigma_{y}$ for SS400 and SM490Y steel was determined based on the document by the Japan Road Association [18]. Moreover, kinematic hardening model was used to consider the Bauschinger's effect, which can consider the reduction of the yield stress during cyclic loading. The stress-strain curve of low yield strength steel $\left(\sigma_{y}=100 \mathrm{MPa}\right)$ was assumed to be elastic-perfectly plastic as shown in Figure 11. The von-Mises yield criterion [22] was used to determine the inelastic state of the material. Direct numerical integration method was used for the earthquake response analyses. A criterion of convergence of analyses was set to have maximum error of less than $0.5 \%$ in an equilibrium equation, which is the default setting in ABAQUS [16]. The Rayleigh damping [23] was used based on the first and second natural periods obtained from a frequency analysis.

\section{Analysis Results}

One of the parameters that may be used to quantify the effect of bolted splices is displacement at the top of the steel frame piers. Figure 12 shows the displacements without bolted splices (A-N), with bolted splices (A-SP), with bolted splices using the low yield strength steel (A-SPD), and with longer bolted splices using the low yield strength steel (ASPD-E) under the JR-Takatori ground motion. It is shown that from comparison of results from A-N and A-SP cases, the existence of bolted splices reduces the maximum displacement of Pier A. In addition, when comparing to A-SPD and A-SPD-E cases, it is shown that displacement from A-SPD case is similar to A-SP case, and A-SPD-E gives the lowest maximum displacement of all cases.

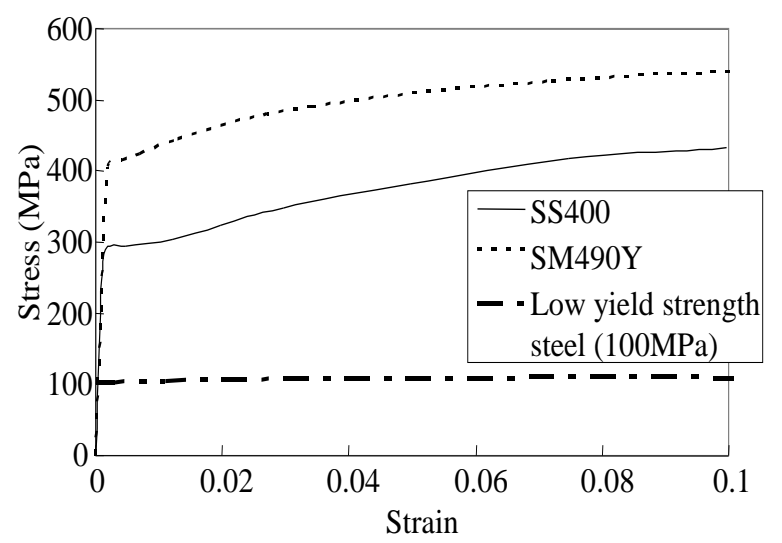

Figure 11. Stress-Strain Curves
Another parameter to quantify the effect of bolted splices on seismic behavior is the magnitude of plastic strain in damage areas. Figure 13 shows the equivalent plastic strain at the center of a web panel of beam-to-column connections, the center of a bolted splice, and the base of the column. As shown, the plastic strain in the column is less when bolted splices are installed. The plastic strain in the column for A-SP and A-SPD cases is almost the same, but the plastic strain becomes smaller when bolted splices become longer. Also, it is also important to note that the equivalent plastic strain of bolted splices for the cases using the low yield strength steel is much larger than that from A-SP case. A larger plastic strain indicates that there is a possibility to dissipate seismic energy by using the low yield strength steel.

Figure 14 shows displacements on Pier B. It can be observed that the maximum response displacement from B-SP case is larger than that from B-N case. Also, it can be observed that the low yield strength steel may reduce deformation. As a result, the maximum response displacement from B-SPD case becomes closer to B-N case and also the maximum response displacement $\mathrm{B}-\mathrm{SPD}-\mathrm{E}$ case is more reduced compared to B-SPD case and less than that from B-N case. Figure 15 shows equivalent plastic strain in Pier B and included plastic strain in the flange at around the section change area between the beam-to-column connections and the beam, where the plastic hinge zone is. It is seen that the damage in the column is less when bolted splices are installed. Those results indicate that bolted splices have a beneficial effect on columns. It is also seen that plastic strain at the section change area is decreased when the low yield strength steel is used. This tendency is more apparent on the results from B-SPD-E case. As a follow up, effects of bolted splices on the plastic hinge zone on beam of Pier $\mathrm{B}$ were investigated in term of deformation of the plastic hinge zone.

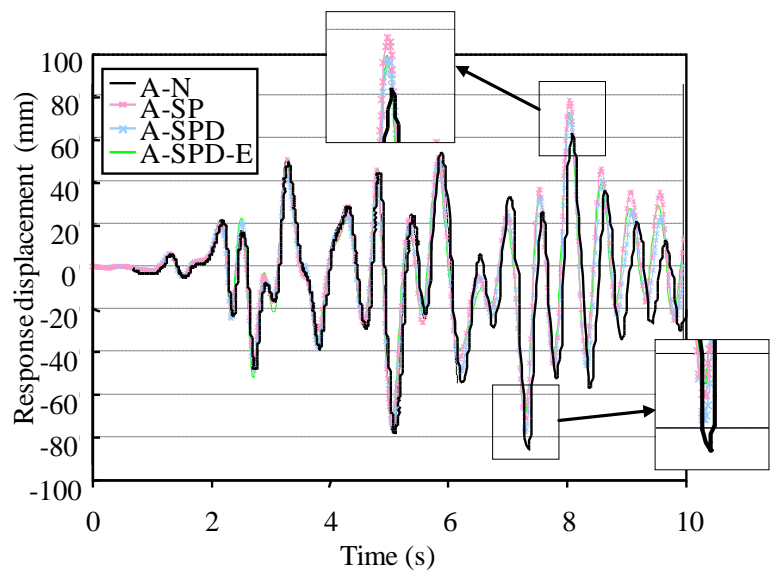

Figure 12. Response Displacements of Pier A 


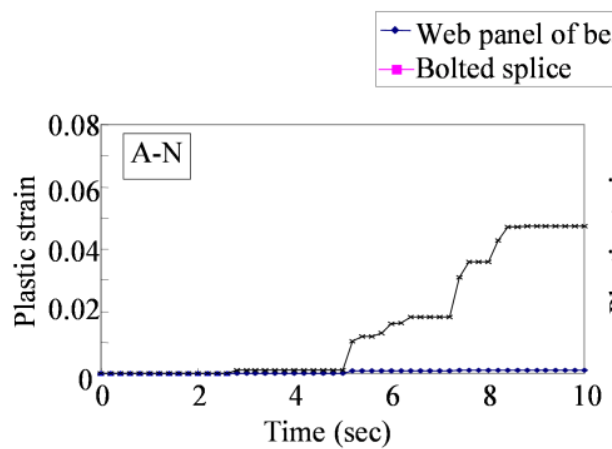

to-column connections * Column base
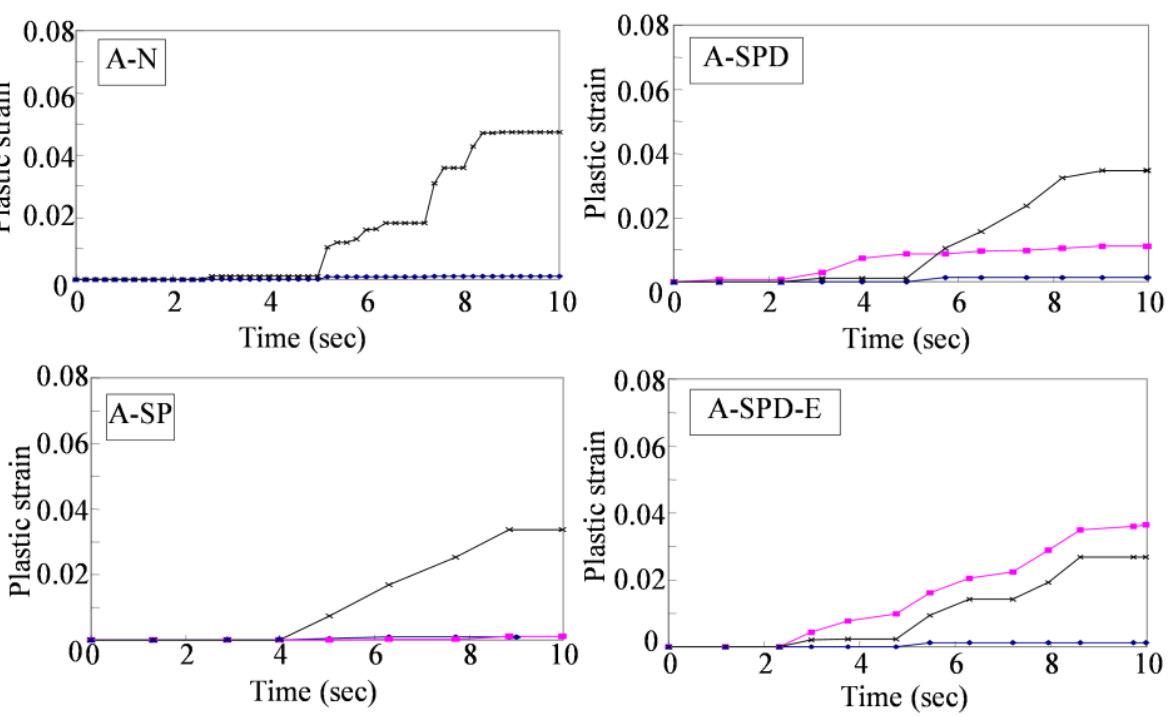

Figure 13. Time History of Equivalent Plastic Strain of Pier A

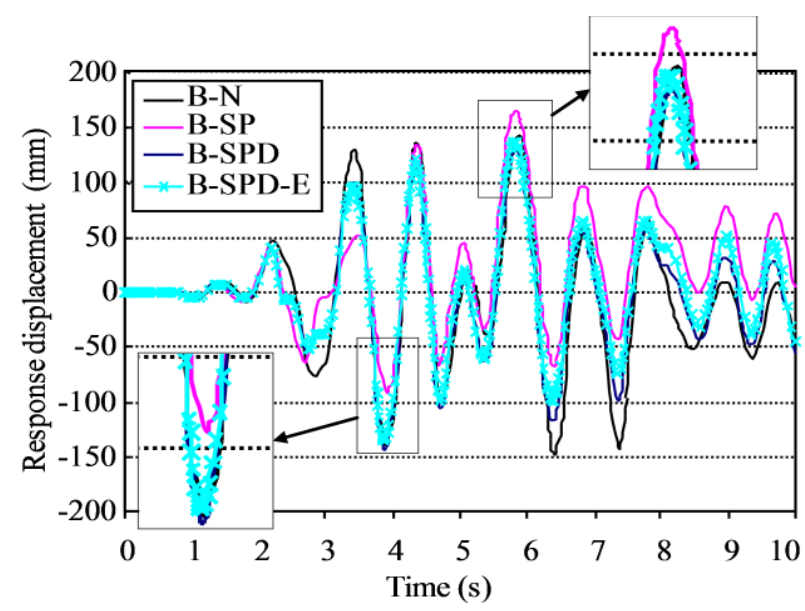

Figure 14. Response Displacements of Pier B

Figure 16 shows deformation and equivalent plastic strain distributions at the end of the analysis, when damage becomes most severe. It is shown that deformation and plastic strain from B-SP case was increased compared to that from B-N case. On the other hand, deformation and plastic strain from BSPD and B-SPD-E cases were decreased compared to B-SP case, and deformation and plastic strain from B-SPD-E case become less than those from B-N case. Therefore, the effect of bolted splices using the low yield strength steel becomes more apparent when bolted splices are longer. The most likely reason is that longer bolted splices can attract more seismic force to bolted splices.

\section{Conclusions}

Effects of bolted splices, which are the most common method for fatigue retrofit works, on seismic behavior of existing steel bridge frame piers have been determined analytically in this paper. Based on the analytical results, several observations can be made:

1. Bolted splices give a slight beneficial effect as shown in the results of Pier A, which has the plastic hinge zone only on the columns. However, bolted splices increase the maximum displacement of Pier B, which has the plastic hinge zones not only on the columns but also on the beam. Bolted splices mostly affect the deformation of the plastic hinge zone on the beam.

2. The beneficial effects of the proposed method to use longer bolted splices using low yield strength steel observed in the analytical results could be due to the attraction of more seismic force to the bolted splices compared to conventional bolted splices and dissipation of seismic energy by the low yield strength steel material. 


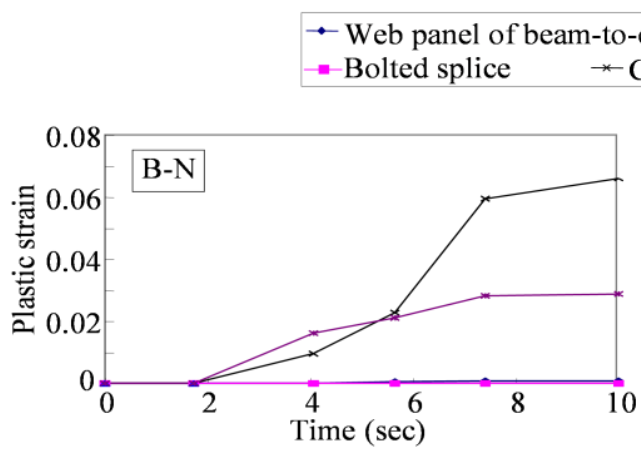

Column base $*$ Section change area
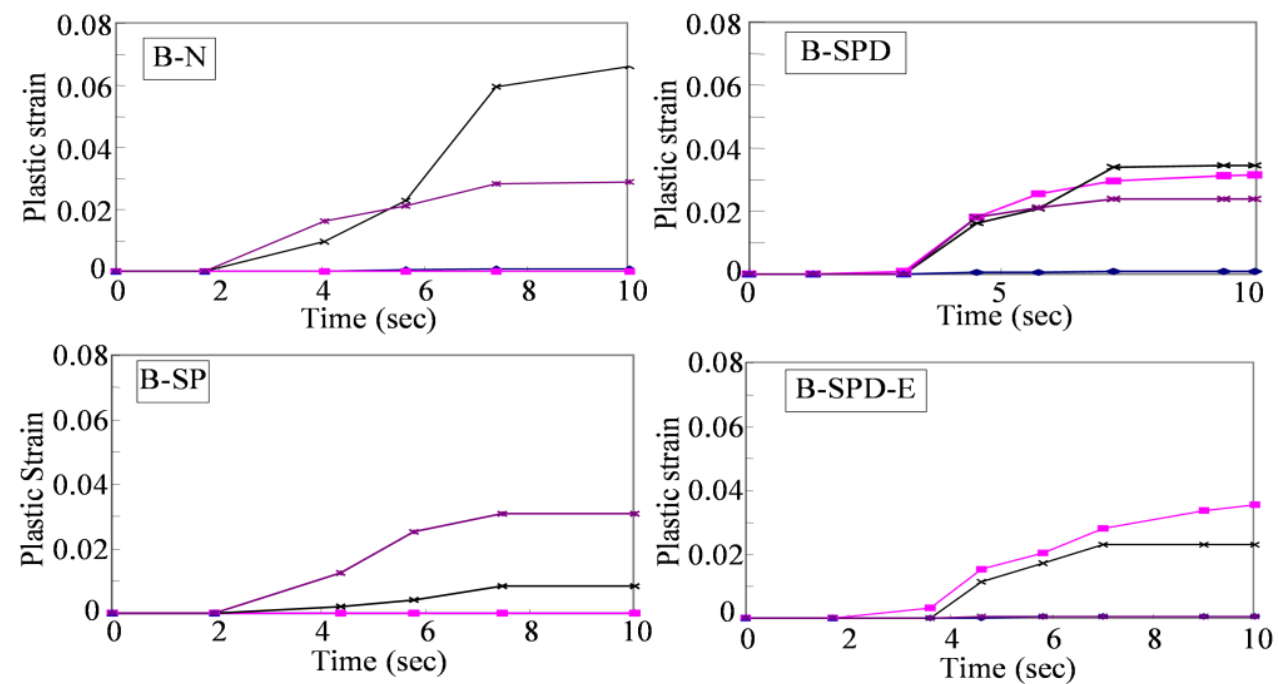

Figure 15. Time History of Equivalent Plastic Strain of Pier B

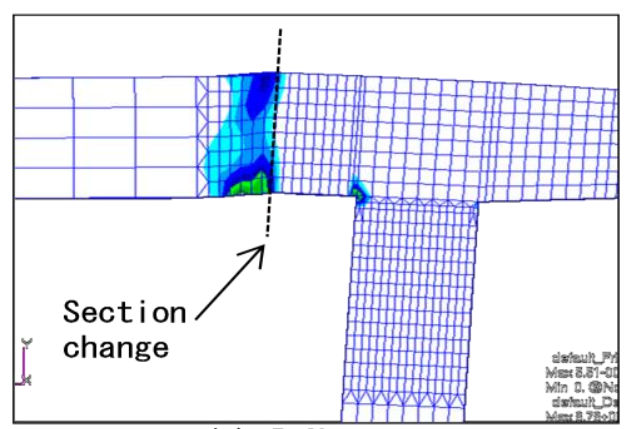

(a) $\mathrm{B}-\mathrm{N}$

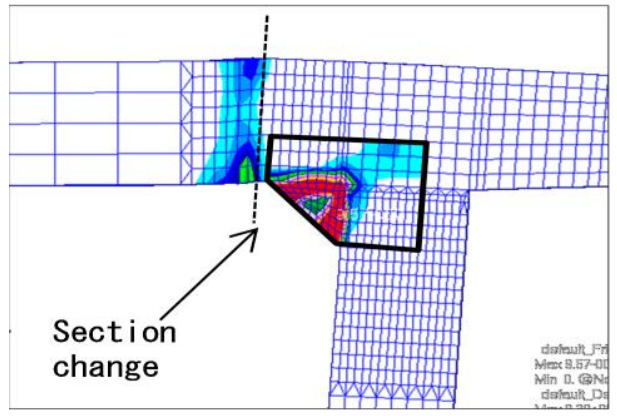

(c) B-SPD

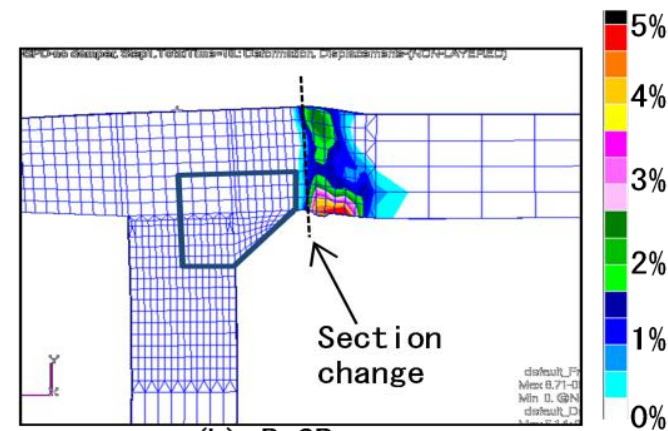

(b) B-SP

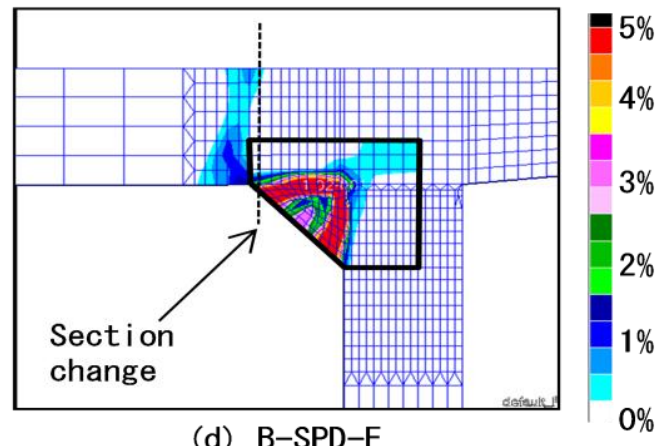

(d) B-SPD-E

Figure 16. Deformation and Equivalent Plastic Strain Distribution of Pier B

\section{Acknowledgments}

The author would like to acknowledge Dr. Chitoshi Miki and Dr. Atsushi Ichikawa, Tokyo Institute of Technology, who provided relevant advice. The author extends his appreciation to Dr. Gary Fry, Texas A \& M, who offered valuable suggestions to this study. The author also acknowledges Hartanto Wibowo for assistance with editing the manuscript.

\section{References}

1. Morikawa, H., Shimozato, T., Miki, C., and Ichikawa, A., Study on Fatigue Cracking in Steel Bridge Piers with Box Section and Temporally Repairing, Journal of Structure Mechanics and Earthquake Engineering, Japan Society of Civil Engineers, 703, 2002, pp. 177-183. (In Japanese). 
2. Miki, C., Ichikawa, A., Sakamoto, T., Tanabe, A., Tokida, H., and Shimozoto, T., Fatigue Performance of Beam-to-Column Connections with Box Sections in Steel Bridge Frame Piers, Journal of Structure Mechanics and Earthquake Engineering, JSCE, 710, 2002, pp. 361-371. (In Japanese).

3. Miki, C., Ichikawa, A., Tanabe, A., and Kinoshita, K., Rib Installation Effects for Fatigue Strengths of Beam-to-Column Connections, IIW Annual Assembly, International Institute of Welding, Doc. XIII-2025-04, 2004.

4. Konishi, T., Miki, C., Hirabayashi, Y., and Shimozato, T., Inspection and Repair of Fatigue Cracks in Steel Bridge Piers, IIW Annual Assembly, International Institute of Welding, Doc. XIII2026-04, 2004.

5. Miki, C. and Hirabayashi, Y., Fatigue Damage Cases due to Inappropriate Fabrication in Steel Bridge Structures, Doboku Gakkai Ronbunshuu A, 63(3), JSCE, 2007, pp. 518-532 (In Japanese).

6. Miki, C., Hirabayashi, Y., Tokida, H., Konishi, T., and Yaginuma, Y., Beam-Column Connection Details of Steel Pier and Their Fatigue Damage Mode, Journal of Structural Mechanics and Earthquake Engineering, 745, JSCE, 2002, pp. 105-119. (In Japanese).

7. Miki, C., Sasaki, E., and Shimozato, T., Seismic Resistance Verification of Fatigue Retrofitted Steel Bridge Bents (A Case Study in the Metropolitan Expressway), Proceedings of the Second International Conference on Urban Earthquake Engineering, Tokyo, Japan, March 7-8, 2005, pp. 77-84.

8. Shimozato, T., Hirabayashi, Y., Hirayama, S., and Sasaki, T., Analytical Study on Load Carrying Capacity of Steel Bridge Pier considering Reinforcement with Bolted Plate and Weld Defect, Journal of Structural Engineering, JSCE, Vol. 54A, 2008, pp. 512-521. (In Japanese).

9. Kinoshita, K., Earthquake Response Analysis of Fatigue Retrofitted Existing Steel Bridge Frame Piers, The 13th JSCE International Summer Symposium, Kyoto, Japan, August 26, 2011, pp. 31-34.

10. Sasaki, E., Miki, C., Ichikawa, A., and Takahashi, K., Behavior of Steel Bridge Frame Piers During Earthquakes, Journal of Structural Engineering, JSCE, Vol. 50A, 2004, pp. 1467-1477. (In Japanese)
11. Miki, C. and Sasaki, E., Fracture in Steel Bridge Piers due to Earthquakes, International Journal of Steel Structures, 5(2), 2005, pp. 133-140.

12. Kinoshita, K., Miki, C., and Ichikawa, A., Study on Seismic Performance of Existing Steel Bridge Frame Piers with Circular Column, Doboku Gakkai Ronbunshuu A, 64(3), JSCE, 2008, pp. 571-587 (In Japanese).

13. Kinoshita, K., Effects of Superstructures on Seismic Behavior of Steel Bridge Frame Piers with Circular Columns, The Sixth International Conference on Bridge Maintenance, Safety and Management, Stresa, Italy, July 8-12, 2012, pp. 3302-3309.

14.Imamura, K. and Takahashi, M., Retrofitting of Existing Piers in Metropolitan Expressway, Bridge and Foundation Engineering, Vol. 33, 1999, pp. 163-165. (In Japanese).

15. Konishi, T., Shimozato, T., Shibuya, A., and Miki, C., Relationship between Bolt Splicing Plate Size and Its Effectiveness of Stress Reduction of Box Section Beam-to-Column Connections, JSCE 58th Annual Assembly, JSCE, I-427, 2003, pp. 853-854. (In Japanese).

16. ABAQUS, ABAQUS/Standard User's Manual, Hibbitt, Karlsson \& Sorensen, 2006.

17. Wibowo, H., Sanford, D.M., Buckle, I.G., and Sanders, D.H., Effects of Live Load on Seismic Response of Bridges: A Preliminary Study, Civil Engineering Dimension, Vol. 14(3), 2012 (Special Edition), pp. 166-172.

18. Japan Road Association, Design Specifications of Highway Bridges, Part V, Seismic Design, Japan Road Association, 2002.

19. JIS G 3101, Rolled Steels for General Structure, Japanese Industrial Standards Committee, 2010. (In Japanese).

20. JIS G 3106, Rolled Steels for Welded Structure, Japanese Industrial Standards Committee, 2008. (In Japanese).

21. Committee of Steel Structures of JSCE and JSSC, Benchmark Test for the Seismic Analysis of Steel Structure and Upgrading of Seismic Design Method, 2000. (In Japanese).

22. Beer, F.P. and Johnston, E.R. Jr., Mechanics of Materials, Second edition, McGraw-Hill, London, 1992.

23. Chopra, A.K., Dynamics of Structures, Second edition, Prentice-Hall, New Jersey, 2001. 